\title{
Algorithm for Automaton Specification for Exploring Dynamic Labyrinths
}

\author{
A. Kumaravel ${ }^{1 *}$ and K. Rangarajan ${ }^{2}$ \\ 'Dean, School of Computing, Bharath University, Chennai-600073; drkumaravel@gmail.com \\ 2Dean, Dept of Computer Applications Bharath University, Chennai-600073; kr221047@gmail.com
}

\begin{abstract}
A variety of interesting problems arise in the study of finite automata that move about in a two dimensional space. The model proposed by Muller [4] is used here to construct new automaton which can explore any labyrinth and escape through the moving or dynamic obstacles inside over the grid. The earlier results were shown for static obstacles distributed over integer grid and the automaton in this case was constructed to interact on the rectangular grid location endowed with four neighborhood directional states. In this paper we allow obstacles moving in discrete steps and verify that the finite automaton with just five printing symbols can escape or find the exit.
\end{abstract}

Keywords: Labyrinths, Finite State Automaton, Printing Mouse, Free Way of Escape.

\section{Introduction}

In an environment of moving obstacles or the presence of cells which put sudden blockage for some time and allow free passage some other time in a maze, one may get into hardship even though a mechanism for coding the locations so far visited is allowed. In this paper we try to answer the following question: 'Can any finite state mouse with the knowledge of dynamic cells, master a labyrinth which has a way of escape at some time?' $[3,5,6]$. We develop an algorithm in the case of dynamic cells exhibiting simple polynomial functions, changing their nature in discrete time steps. Difficulty is caused by the dynamic cells in a labyrinth. Moving a wall from a cell may introduce a way of escape and the introduction of a wall may totally disconnect the way of escape or reduce the number of choices for branching, the occurrences of these events in the labyrinth demand the mouse to be more 'dynamic' in the sense that it has to avoid the collision on walls or avoid getting trapped under the walls $[1,2,7]$. This of course is influenced in part by the problem specification. In general, without any extra memory, a printing mouse cannot master any labyrinth of above type as these factors cannot be controlled (rather predicted) with its limited capability. Even if one is able to prescribe the motion of the walls in terms of simple functions of discrete time units, finding an exit depends very much on the coincidence of the presence of the mouse in one of the cells which exactly gives a free way to escape.

Hence synchronizing the motion in the labyrinth and the motion of the mouse is highly necessary in order to represent the knowledge for the mouse for mastering such labyrinths. However, if a labyrinth allows some 'static portion', that is, gaps between the moving walls, then it is shown such class of labyrinths can be mastered. In this paper, in the following sections we formulate such class of dynamic labyrinths and give the algorithm which masters any labyrinth in that class.

\section{Methodology}

We follow the traditional Tremaux Algorithm [4] to master the given maze encoded over the integer grid. Integer

* Corresponding author:

A. Kumaravel (drkumaravel@gmail.com) 
Cartesian product to locate the obstacle and free way by a binary function on the grid is considered for simple specification of main algorithm. The automaton which has the capability of interacting or connected to this function on the grid is constructed using another output function. The proof for verification of this algorithm is done part by part through set of lemmas as seen section 3 .

\section{State Space Explosion and Minimization}

Endowing enormous amount of states to the automaton may lead to poor performance. Hence we identify the set of classes of states like forward or backward or stop in all four direction while try to move on the rectangular maze. Hence a top down approach is appropriate in our context. The complexity of our automaton is measured in terms of finite number of obstacles distributed on the grid.

If all the obstacles are covered inside a minimal square $\mathrm{S}$ of side $\mathrm{n}$, then the complexity will be calculated as follows. In the worst case if $S$ contains a maximal spiral path that can be tightly fitted inside $S$ and it can have a path of length bounded by,

$[n+(n-1)+\ldots+1]$ and for all the inner squares following the same argument we have eventually the complexity to be $\mathrm{O}\left(\mathrm{n}^{2}\right)$.

Here, we achieve minimum set of output signals or printing symbols as one may not further minimize due to four distinct directions in a rectangular grid and one stopping or blocking condition. Any path configuration generated by the automaton has a prefix of printing symbols and infinitely many free symbols at the tail end in case of the open maze. In case of closed maze we have finite path configuration made up of blocking symbols. Hence the output generated by the main algorithm is characterized as either escapable or not by looking at either infinite open way or finite blocked way of escape.

\section{Basic Notations, Definitions and Algorithm}

In this section we define a class of labyrinths and a suitable finite state mouse which masters this class.

Definition 4.1: Let $L$ be a function $Z^{2} \mathrm{xN} \rightarrow\{\mathrm{X}, \mathrm{F}\}$. We say $\mathrm{L}$ is a dynamic labyrinth if the following conditions hold. (i) The subset $T$ of $Z^{2}$ given by

$\mathrm{T}=\left\{\mathrm{P} \varepsilon \mathrm{Z}^{2} / \mathrm{L}(\mathrm{p}, \mathrm{t})=\mathrm{X}\right.$ for $\mathrm{P} \varepsilon \mathrm{Z}^{2}$ and some $\left.\mathrm{t} \varepsilon \mathrm{N}\right\}$ is finite. $\mathrm{T}$ denotes cells on the labyrinth which are wall cells at least once.

(ii) There exists a subset $\mathrm{T}$ ' of $\mathrm{T}$ such that

(a) $\mathrm{L}(\mathrm{p}, \mathrm{t}=1)=\mathrm{X}$ for every PeT'

(b) $\mathrm{L}(\mathrm{P}, \mathrm{t})=\mathrm{X}==\mathrm{L}(\mathrm{P}, \mathrm{t}+1)=\mathrm{F}$ and

(c) $\mathrm{L}(\mathrm{P}, \mathrm{t}+2)=\mathrm{X}$ for every $\mathrm{t} \varepsilon \mathrm{N}$ and $\mathrm{P} \varepsilon \mathrm{T}^{\prime}=\mathrm{P}+\mathrm{r} \varepsilon$ T' for every PeT'.

Varying these finite subsets $\mathrm{T}$ and $\mathrm{T}$ ' of $\mathrm{Z}^{2}$, we get the class $\varnothing$ of all such labyrinths. We call the cells in $\mathrm{T}^{\prime}$ as dynamic cells in L. there can be some static wall cells also and some static free cells, $m$, the inscription function as in [1], is defined on $Z^{2} \times \mathrm{N}$ such that

$$
\begin{aligned}
& \mathrm{m}: \mathrm{Z} \times \mathrm{Z} \times \mathrm{N} \Rightarrow \mathrm{I} \\
& (\mathrm{m}(\mathrm{P}, \mathrm{t}) \mathrm{X} \leftrightarrow \mathrm{L}(\mathrm{P}, \mathrm{t})=\mathrm{X})
\end{aligned}
$$

We put $\mathrm{m}^{\mathrm{t}}(\mathrm{P})$ instead of $\mathrm{m}(\mathrm{p}, \mathrm{t})$. A finite state mouse suitable for this environment is considered to be a sequential machine $\mathrm{U}_{5}^{c}=\left(\mathrm{S}, \mathrm{I}, \mathrm{O}, \delta, \lambda, \mathrm{s}_{\mathrm{in}}\right)$

We take the set of states $\mathrm{S}$ as S1 U S2 U S3 U $\left\{\mathrm{s}_{\text {in }}\right\}, \mathrm{I}=\{\mathrm{X}$, F $\} U\{N, E, S, W, B\}$, where S1, S2, S3 will be defined later.

$\mathrm{U}_{5}^{c}$ makes use the set $\{\mathrm{N}, \mathrm{E}, \mathrm{S}, \mathrm{W}, \mathrm{B}\}$ as its print alphabet.

Definition 4.2: The output function is defined from $S \mathrm{X}$ I to (D $U\{\varepsilon\} X$ (I $U\{\varepsilon\}$ ) where $\varepsilon$ is empty symbol and $\lambda$ satisfies the following conditions.

$$
\begin{aligned}
& \lambda\left(\mathrm{S}, \mathrm{m}^{\mathrm{t}}(\mathrm{P})\right)=(\varepsilon, \mathrm{Y}) \rightarrow \mathrm{y}=\varepsilon \text { and } \\
& \mathrm{m}^{\mathrm{t}}(\mathrm{P})=\mathrm{m}^{\mathrm{t}+1}(\mathrm{P}) \text { for } \mathrm{t} \varepsilon \mathrm{N} .
\end{aligned}
$$

$\mathrm{m}^{\mathrm{t}}$ is the inscription on $\mathrm{L}$ at time $\mathrm{t}$. this definition tells that output will contain $\varepsilon$. $\mathrm{U}^{c}$ stays at $\mathrm{P}$ and present marking at $\mathrm{P}$ is not altered. We are already familiar with the output function $\lambda$ from $S x$ I to $D x$ I as in [4]. This inclusion of $\varepsilon$ here in every coordinate, in the range of $\lambda$ is to make the mouse stay at a cell in the successive configuration without altering the contents in the present cell. Suppose the mouse is in a cell $\mathrm{p}$ at time $\mathrm{t}$ and moves to the cell $\mathrm{p}+\mathrm{r}$ in the direction $\mathrm{r}$, we assume the mouse is at $\mathrm{p}+\mathrm{r}$ exactly at time $\mathrm{t}+1$. That is, it takes unit time to move from a cell to the neighboring cell. Moreover, by ii. b of definition 2.1, the cells in T' experience the transition of $\mathrm{X}$ to $\mathrm{F}$ or $\mathrm{F}$ to $\mathrm{X}$ in unit time.

\subsection{Formulation of the Problem and the Algorithm}

The algorithm for $\mathrm{U}_{5}^{c}$ is based on the Tremaux algorithm as well as a method for dealing with the dynamic cells in T'. As far as there is no disturbance, that is, if the mouse 
is somewhere in $\mathrm{Z} / \mathrm{T}$ ' it follows the Tremaux algorithm with unit delay in each cell, anticipating any occurrence of a dynamic neighbour. If there is no branching except through a dynamic neighbour, it passes through this neighbour quickly, that is in unit time to some other cell before it gets blocked.

Suppose from a cell $\mathrm{P}$, a neighbouring cell $\mathrm{P}+\mathrm{r}$ in direction $\mathrm{r}$, belongs to $\mathrm{T}$. standing at $\mathrm{P}$, the mouse may see either $\mathrm{X}$ or $\mathrm{F}$ in $\mathrm{P}+\mathrm{r}$ depending upon the time it reached $\mathrm{P}$. at the time of arrival to $\mathrm{P}+\mathrm{r}$, it should contain $\mathrm{F}$. call it as event $\mathrm{E}$. to get this event $\mathrm{E}$ we observe that there are two possibilities.

(i) At time $\mathrm{t}$, suppose the mouse is at $\mathrm{P}$ and $\mathrm{P}=\mathrm{r}$ contains $\mathrm{X}$.

i.e. $\mathrm{m}^{\mathrm{t}}(\mathrm{P}+\mathrm{r})=\mathrm{X}$

Then, $\mathrm{m}^{\mathrm{t}+1}(\mathrm{P}+\mathrm{r})=\mathrm{F}$

$\mathrm{m}^{\mathrm{t}+2}(\mathrm{P}+\mathrm{r})=\mathrm{X}$

$\mathrm{m}^{\mathrm{t}+3}(\mathrm{P}+\mathrm{r})=\mathrm{F}$

In this case for event $\mathrm{E}$ to occur mouse waits for two time units at $\mathrm{P}$.

(ii) At time $t$, suppose the mouse is at

$\mathrm{P}$ and $\mathrm{P}+\mathrm{r}$ contains $\mathrm{F}$.

i.e. $\mathrm{m}^{\mathrm{t}}(\mathrm{P}+\mathrm{r})=\mathrm{F}$

Then, $\mathrm{m}^{\mathrm{t}+1}(\mathrm{P}+\mathrm{r})=\mathrm{X}$

$\mathrm{m}^{\mathrm{t}+2}(\mathrm{P}+\mathrm{r})=\mathrm{F}$

In this case for even $\mathrm{T}$ to occur mouse waits for a time unit at $\mathrm{P}$.

To enter, $\mathrm{P}+\mathrm{r}$, the mouse makes appropriate delay, namely, for case (i) two time unit delay and for (ii) one time unit delay to face the event $\mathrm{E}$.

Main algorithm presents rules for transition of any state in S1 to another state in the set S1U S2 where

$$
\begin{aligned}
& \mathrm{S} 1=\left\{\text { for }_{\mathrm{r}} \text { back }_{\mathrm{r}} / \mathrm{r \varepsilon D}\right\} \\
& \mathrm{S} 2=\left\{\text { run-for }_{\mathrm{r}}, \text { run-back }_{\mathrm{r}} / \mathrm{r \varepsilon D}\right\}
\end{aligned}
$$

We deal with the waiting requirement with a set of delay states

$$
\mathrm{S} 3=\left\{\text { delay } \mathrm{i}-\text { for }_{\mathrm{r}} \text {, delay } \mathrm{i}-\mathrm{back}_{\mathrm{r}} / \mathrm{r \varepsilon D}, \mathrm{i}=1,2\right\}
$$

We use the states delay-i-for, delay-i-back $\mathrm{r}_{\mathrm{r}}$ for $\mathrm{i}=1,2$ for the first case and for the second case

A transition $s \rightarrow s$ ' from S1 to S2 means a set of transitions as follows.

$$
\begin{aligned}
& \mathrm{S} \rightarrow \mathrm{S} 1 \rightarrow \mathrm{S}^{\prime} \text { or } \\
& \mathrm{S} \rightarrow \mathrm{S} 1 \rightarrow \mathrm{S} 2 \rightarrow \mathrm{S}^{\prime} \text { where } \\
& \mathrm{S} 1, \mathrm{~S} 2 \varepsilon \mathrm{S} 3 .
\end{aligned}
$$

These two types of transitions are for case (i) and case (ii) respectively. This is shown in the Figure 4.1.

We assume that the mouse starts at $\mathrm{P}_{0}$ which is not in T'. Let $\mathrm{P}_{0}$ be the origin in $\mathrm{Z}^{2}$

\subsection{Algorithm for $\mathrm{U}_{5}{ }_{5}$}

Start: [Assertion: Present configuration is $\left(\mathrm{S}_{\mathrm{in}}, \mathrm{P}, \mathrm{L}\right)$ ]

1. If there is a free neighbour in the direction $r$, goto the state 'for' ${ }_{r}$ otherwise goto the state start-delay.

Start - delay:

1. If there is a free neighbour in the direction $\mathrm{r}$, after a delay, goto the state 'run-for' and go to the cell $\mathrm{P}+\mathrm{r}$.

2. Otherwise stop.

[Assertion: Present configuration is (s, P, m)

$$
\begin{aligned}
& \mathrm{S}=\text { for }_{\mathrm{r}} \rightarrow \mathrm{m}(\mathrm{P})=\mathrm{F} ; \mathrm{r}^{\prime \prime}=-\mathrm{r} \\
& \left.\mathrm{S}=\text { back }_{\mathrm{r}} \rightarrow \mathrm{m}(\mathrm{P}) \varepsilon \mathrm{D} ; \mathrm{r}^{\prime \prime}=\mathrm{m}(\mathrm{P})\right]
\end{aligned}
$$

a.1 If there is no change in $\mathrm{m}\left(\mathrm{P}+\mathrm{r}^{\prime}\right)$ in the direction $r^{\prime} \varepsilon D$, for $r^{\prime} \neq-r$ and $P+r^{\prime}$ is free, go to the state for $r_{r^{\prime}}$ print ' $-r$ ' on $p$ if $s=$ for $_{r}$ (Do not print if $s=$ back $\left._{\mathrm{r}}\right)$; go to the cell $\mathrm{P}+\mathrm{r}$ '

a.2 If there is a change in $m\left(P+r^{\prime}\right)$ in the direction $r^{\prime} \varepsilon D$, for $r^{\prime} \neq-r$ go to the state run-for ${ }_{r}^{\prime}$ then print ' $-r$ ' on $P$; if $s=$ back, do not print on $P$ ). Go to the cell $P+r$ '.

b.1 If there is no change in $\mathrm{m}(\mathrm{P}+\mathrm{r}$ ") in the direction $r$ " and $\mathrm{P}+\mathrm{r}$ " is free go to the state for "'; print ' $\mathrm{B}$ ' on $\mathrm{P}$ and goto the cell $\mathrm{P}+\mathrm{r}$.

b.2 If there is a change in $\mathrm{m}(\mathrm{P}+\mathrm{r}$ ") in the direction $\mathrm{r}$," goto the state run-for ${ }_{r}$ " if $s=$ for $_{r}$ and to the state

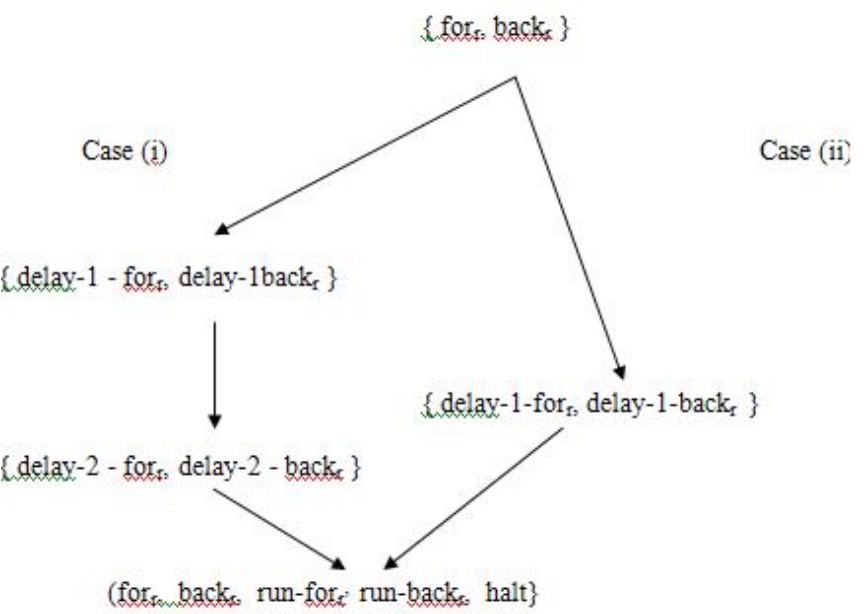

Figure 4.1 State Transition Tree. 
run-back" if $s=$ back $_{r}$ print $\mathrm{B}$ on $\mathrm{P}$ and goto the cell $\mathrm{P}+\mathrm{r}$ ".

c.1 If there is no change in $\mathrm{m}(\mathrm{P}+\mathrm{r}$ ") in the direction $\mathrm{r}$ " and $\mathrm{P}+\mathrm{r}$ " is not free but marked (i.e., $\mathrm{m}(\mathrm{P}+\mathrm{r}$ ") $\varepsilon \mathrm{D}$ ) goto the state back", print $\mathrm{B}$ on $\mathrm{P}$ and goto $\mathrm{P}+\mathrm{r}$ ".

c.2 If there is no change in $\mathrm{m}(\mathrm{P}+\mathrm{r}$ ") in the direction $r$ " and $\mathrm{P}+\mathrm{r}$ " is blocked, stop.

Action in the states run-for ${ }_{r}$ and run-back ${ }_{r}$ is described as follows.

[Assertion: $\mathrm{s}=$ run-for $_{\mathrm{r}}$ and run-back $\mathrm{r}_{\mathrm{r}} \rightarrow \mathrm{m}(\mathrm{P})=\mathrm{F}$ ]

d.1 Go to the state for $r_{r^{\prime \prime}}$ if $\mathrm{P}+\mathrm{r}^{\prime}$ is free and go to $\mathrm{P}+\mathrm{r}$ '.

d.2 Go to the state back $\mathrm{r}^{\prime \prime}$ if $\mathrm{P}+\mathrm{r}^{\prime}$ is marked and go to $\mathrm{P}+\mathrm{r}$ '.

\section{Invariance of the Main Algorithm}

We define dynamic partially marked way of escape to study some properties of $\mathrm{U}_{5}^{c}$. This way of escape is similar to the ways of escape defined in the previous chapters except this way contains some cells which always change the inscription from $\mathrm{X}$ to $\mathrm{F}$. The definition is made as follows:

\section{DEFINITION 5.1:}

(a) $(\mathrm{W}, \mathrm{k})$ is said to be a dynamic partially marked way of escape for the configuration $(s, P, m)$ if the following conditions are true.

1. $\mathrm{W}$ is an infinite way i.e. $\mathrm{w}=\langle\mathrm{Pi} / \mathrm{i}$ No $>$ $\mathrm{Po}=\mathrm{P}$ and $\mathrm{P}_{\mathrm{i}+1}=\mathrm{Pi}+\mathrm{D}$, for $\mathrm{i}>0$.

2. $\mathrm{i}>0, \mathrm{j}>0 \rightarrow \mathrm{Pi} \neq \mathrm{Pj}$ for $\mathrm{i} \neq \mathrm{j}$

3. $\mathrm{k \varepsilon N}$

4. $\mathrm{i}<\mathrm{k} \rightarrow \mathrm{m}(\mathrm{Pi}) \varepsilon \mathrm{DU}\{\mathrm{X}\}$. Moreover $\mathrm{m}^{\mathrm{t}}(\mathrm{Pi})=\mathrm{X} \rightarrow \mathrm{m}^{\mathrm{t}+1}(\mathrm{Pi})=\mathrm{F}$.

5. $\mathrm{i}>\mathrm{k}, \mathrm{m}^{\mathrm{t}}(\mathrm{Pi})=\mathrm{F}$ for ecery $\mathrm{t}$ in

6. If $\mathrm{k}>1$ and $\mathrm{s} \varepsilon\left\{\right.$ for $_{\mathrm{r}}$, run-for , $\left._{\mathrm{r}}\right\} \rightarrow \mathrm{P}_{1}=\mathrm{P}-\mathrm{r}$

7. If $\mathrm{k}>1$ and $\mathrm{s} \varepsilon\left\{\right.$ back $_{\mathrm{r}}$ run-back $\left._{\mathrm{r}}\right\} \rightarrow \mathrm{P}_{1}=\mathrm{P}+\mathrm{r}$

8. If $\mathrm{k}>1$ and $\mathrm{s} \varepsilon$ \{delay-i-for ${ }_{\mathrm{r}}$ delay $\mathrm{i}-$-back $\left._{\mathrm{r}}\right\} \rightarrow \mathrm{P}_{1}$ $=\mathrm{P}$.

(b) If $(\mathrm{W}, 1)$ is a dynamic partial marked way of escae for the configuration ( $\mathrm{s}, \mathrm{P}, \mathrm{m})$, it is called dynamic free way of escape for (s, P, m).

Definition 5.2: An open labyrinth is one which has at least one partial mark way $\mathrm{W}$ of escape, treating all the dynamic cells in $\mathrm{W}$ as free.

The following results are consequences of algorithm 4.1.

LЕмма 5.3: $\mathrm{U}_{5}^{c}$ reaches every point in $\mathrm{Z}^{2}$ at most four times.
Proof: We can partition $Z^{2}$ into three sets with respect to given labyrinth $\mathrm{L}$ as follows.

$$
\begin{aligned}
& A 1=\left\{P \varepsilon Z^{2} / L(P, t)=X \text { for every } t \varepsilon N\right\} \\
& A 2=\left\{P \varepsilon Z^{2} / L(P, t)=F \text { for every } t \varepsilon N\right\} \text { and } \\
& A 3=\left\{P \varepsilon Z^{2} / L(P, t)=X \text { for } t \text { is even and } L(P, t)=F\right. \text { for } \\
& t \text { is odd }\}
\end{aligned}
$$

There is no loss of generality for, if $\mathrm{L}(\mathrm{P}, \mathrm{t})=\mathrm{x}$ for $\mathrm{t}$ odd then $\mathrm{L}(\mathrm{P}, \mathrm{t})=\mathrm{F}$ for $\mathrm{t}$ even from the definition of $\mathrm{T}$. This is a similar situation and hence is not treated again.

There can be no other possibility for $\mathrm{A}_{3}$ under the conditions of ' $\mathrm{T}$ '

We consider three cases separately as follows.

CASE 1: $\mathrm{P} \varepsilon \mathrm{A}_{1}$ In this case $\mathrm{P}$ cannot be reached by $\mathrm{U}^{\mathrm{c}}{ }^{\text {. }}$

CASE 2: $\mathrm{P} \varepsilon \mathrm{A}_{2}$ At the first time, $\mathrm{P}$ is reached as a free point. When the mouse leaves this cell $\mathrm{p}$ for the first time, $\mathrm{P}$ is marked (by a.2). For the next time, it can reach $\mathrm{P}$ in two different ways from a neighbour say $\mathrm{P}_{1}$. It can be either in the state back $\mathrm{r}_{\mathrm{r}} \mathrm{P}_{1}$ is in $\mathrm{A}_{2}$ or in one of the states in $\left\{\right.$ run-for ${ }_{\mathrm{r}^{\prime}}$ run-back $\mathrm{r}_{\mathrm{r}}$ if $\mathrm{P}_{1}$ is in $\mathrm{A}_{3}$.

CAse 2.1: $\mathrm{P}_{1} \varepsilon \mathrm{A}_{3}$ We know $\mathrm{P}_{1}$ will be blocked when $\mathrm{U}_{5}^{c}$ goes from $\mathrm{P}_{1}$ to $\mathrm{P}$. (by b.1 and c.1). If all the neighbours are in $A_{2}$ it can reach $P$ in this way at most four times.

CASE 2.2: $\mathrm{P}_{1} \varepsilon \mathrm{A} 3$

It implies that $\mathrm{P}_{1}+\mathrm{r} \varepsilon \mathrm{A}_{2}$ or $\mathrm{A}_{1}$

If $\mathrm{P}_{1}+\mathrm{r} \varepsilon \mathrm{A}_{2}$, then $\mathrm{P}_{1}+\mathrm{r}$ is marked when it goes to $\mathrm{P}_{1}$ from $\mathrm{P}_{1}+\mathrm{r}$ (by step a.2).

CAse 3: $\mathrm{P} \in \mathrm{A}_{3}$ Any neighbour $\mathrm{P}^{\prime}$ of $\mathrm{P}$ is not in $\mathrm{A}_{3}$

Hence $\mathrm{U}_{5}^{\mathrm{c}}$ can reach $\mathrm{p}$; through the 'passage, $\mathrm{P}$ through the state transition run-for $r_{r} \rightarrow$ for $_{r^{\prime}}$ for some $r \varepsilon D$ and $r^{\prime}=-r$.

In this move $\mathrm{U}_{5}^{c}$ does not make any printing on $\mathrm{P}$. But the inscription on $\mathrm{P}$ is either marked or it becomes marked in the next time unit.

Since this event will be the same any of the neighboring cells $\mathrm{p}$, all of the neighbors get blocked if there is no way to escape (that is, given labyrinth $\mathrm{L}$ is not open). If $\mathrm{L}$ is open, $\mathrm{p}$ is surrounded by wall cells or by cells with symbols " $\mathrm{B}$. Hence even if $\mathrm{P}$ is always free at even time units, it can be reached at most four times.

Hence there exist at most four paths in the four directions like the path connecting $\mathrm{P}_{1} \mathrm{P}_{1}, \mathrm{P}_{1}+\mathrm{r}$ with $\mathrm{P}_{1}$ being a dynamic cell.

Hence, the Lemma. 
LemMA 5.4: $\mid\left\{\mathrm{P}_{\mathrm{i}} \varepsilon \mathrm{W} \mid \mathrm{m}^{\mathrm{t}}\left(\mathrm{P}_{\mathrm{i}}\right)=\mathrm{X}\right.$ and $\left.\mathrm{m}^{\mathrm{t}+1}\left(\mathrm{P}_{\mathrm{i}}\right)=\mathrm{F}\right\} \mid \leq \mathrm{k} / 2$ for $\mathrm{i}<\mathrm{k}$ in the infinite dynamic partial marked way of escape $(\mathrm{W}, \mathrm{k})$ for any configuration $(\mathrm{s}, \mathrm{P}, \mathrm{m})$ of $\mathrm{U}_{5}^{\mathrm{c}}$.

Proof: (w, k) satisfies a 4 of the definition 4.1 with the above property. This is because $\left|\mathrm{A}_{3}\right|<\left|\mathrm{A}_{1}\right|\{$ since T, C T $\} \mathrm{k}$ is the upper-bound after which every cell is in $\mathrm{w}$.

That is, $\mathrm{P}_{\mathrm{k}+1}, \mathrm{P}_{\mathrm{k}+2} \ldots \ldots$ have free inscriptions.

If $\mathrm{m}_{\mathrm{t}}\left(\mathrm{P}_{\mathrm{i}}\right)=\mathrm{X}$ for $\mathrm{i}<\mathrm{k}$ then $\mathrm{P}_{\mathrm{i}} \varepsilon \mathrm{T}$.

For any $\mathrm{P}_{\mathrm{i},} \mathrm{P}_{\mathrm{i}+1}$ is the neighbour of $\mathrm{P}_{\mathrm{i}}$ (by case a.1 of definition 4.1).

Hence, $\mathrm{P}_{\mathrm{i}+1} \varepsilon \mathrm{T}$.

Hence when we count all $\mathrm{P}_{\mathrm{i}}$ for $\mathrm{i}<\mathrm{k}$ and $\mathrm{m}\left(\mathrm{P}_{\mathrm{i}}\right)=\mathrm{x}$, it amounts to at most $\mathrm{k} / 2$.

The following lemma shows that the mouse is not trapped in any dynamic cell $\mathrm{p}$. That is, when $\mathrm{m}^{\mathrm{t}}(\mathrm{P})=\mathrm{X}, \mathrm{P}$ cannot be in the configuration at the time $t$ in the behavior of $\mathrm{U}_{5}^{\mathrm{c}}$.

Lemma 5.5: If $\left(\mathrm{s}^{\mathrm{t}}, \mathrm{P}^{\mathrm{t}}, \mathrm{m}^{\mathrm{t}}\right)$ is a configuration in an open labyrinth $L$ with $\mathrm{s}^{\mathrm{t}} \varepsilon\left\{\right.$ run - for $_{\mathrm{r}}$, run-back $\left._{\mathrm{r}} \mid \mathrm{r} \varepsilon \mathrm{D}\right\}$, then $\mathrm{m}_{\mathrm{t}}$ $(\mathrm{P}+\mathrm{r}) \varepsilon\{\mathrm{F}\} \mathrm{U} \mathrm{D}$.

Proof: $\mathrm{S}_{\mathrm{t}} \varepsilon\left\{\right.$ run-for $_{\mathrm{r}}$, run-back $\left.{ }_{\mathrm{r}} \mid \mathrm{r} \varepsilon \mathrm{D}\right\}$

Hence, there is an event in which there exists at least one neighbour cell which is free or marked. Then the state run-for ${ }_{r}$ or run-back is considered, depending upon the present state being for ${ }_{\mathrm{r}}$ or back or back $_{\mathrm{r}}$ in delay state.

If the previous state is for $_{r}$ then the neighbour in direction $-r$ has already been marked.

If the previous state is back $_{\mathrm{r}}$, the cell in the direction $\mathrm{r}$ is blocked. If this is the case for all $r \varepsilon D$, then $L$ is closed which is a contradiction.

Hence $\mathrm{m}_{\mathrm{t}}(\mathrm{P}+\mathrm{r}) \varepsilon\{\mathrm{F}\} \mathrm{U} \mathrm{D}$.

LemMA 5. 6: If $(\mathrm{w}, \mathrm{k})$ is the partial marked dynamic way of escape for the configuration $\left(\mathrm{s}^{\mathrm{t}}, \mathrm{P}^{\mathrm{t}}, \mathrm{m}^{\mathrm{t}}\right)$ for $\mathrm{s}^{\mathrm{t}} \varepsilon \mathrm{S} 1$, then there exists a successor configuration $\left(\mathrm{s}^{\mathrm{t}+1}, \mathrm{P}^{\mathrm{t}+1}, \mathrm{~m}^{\mathrm{t}+1}\right)$ with the partial marked dynamic way of escape $\left(w^{\prime}, k^{\prime}\right)$ such that $\mathrm{s}^{\mathrm{t}+1} \varepsilon \mathrm{s}_{3}$ and $\mathrm{P}^{\mathrm{t}+1}=\mathrm{P}^{\mathrm{t}}$.

Proof: The next state for any state in $\mathrm{S} 1$ is in $\mathrm{S} 3$ as discussed in section 3. Any delay-sate in $\mathrm{S} 3$ makes $\mathrm{U}_{5}^{\mathrm{c}}$. Wait in the present cell, that is $\mathrm{p}^{\mathrm{t}}$.

Here, we construct ( $\left.w^{\prime}, k^{\prime}\right)$ same as ( $\left.w, k\right)$.

LEMmA 5.7: If $(w, k)$ is the partial marked dynamic way of escape in an open labyrinth $\mathrm{L}$ for the configuration $\left(\mathrm{s}^{\mathrm{t}}, \mathrm{P}^{\mathrm{t}}, \mathrm{m}^{\mathrm{t}}\right)$ for $s^{t} \varepsilon S 3$, then there exists a successor configuration $\left(\mathrm{s}^{\mathrm{t}+1}, \mathrm{P}^{\mathrm{t}+1}, \mathrm{~m}^{\mathrm{t}+1}\right)$ with the partial marked dynamic way of escape ( $w^{\prime \prime}, k^{\prime \prime}$ ) such that $s^{t+1} \varepsilon S 1 U_{5}^{c}$ and $P^{t+1} \neq \mathrm{P}^{t . .}$
Proof: For each case in the algorithm we shall construct the following dynamic ways of escape which satisfy the conditions in 4.1.

CASE A.1: $\mathrm{S}^{\mathrm{t}+1}=$ for $_{\mathrm{r}}$, and $\mathrm{P}^{\mathrm{t}+1}=\mathrm{P}^{\mathrm{t}}+\mathrm{r}^{\prime}$ for some $\mathrm{r}^{\prime} \varepsilon \mathrm{D}$.

If $\mathrm{P}^{t+1}$ is already in $\mathrm{w}$, then $\mathrm{w}^{\text {" }}$ is obtained by taking $\mathrm{p}^{\mathrm{t}+1}$ as new $P$ rest of the point in $w$ as the free way starting from po. If $\mathrm{p}^{\mathrm{t}+1}$ is not already in $\mathrm{w}$, when $\mathrm{w}^{\text {" }}$ is obtained by adding $\mathrm{p}^{\mathrm{t}+1}$ to remaining points in $\mathrm{w}$.

CASE A.2: $\mathrm{S}^{\mathrm{t}+1}=$ for ${ }_{\mathrm{r}}$ "and $\mathrm{P}^{\mathrm{t}+1}=\mathrm{Pr}^{\mathrm{r}}$ for $\mathrm{r}$ " $=-\mathrm{r}$. In this case $\mathrm{w}^{\text {" }}$ is obtained by remaining $\mathrm{p}^{t}$ in $\mathrm{w}$ and retaining the remaining points in $\mathrm{w}$.

CASE B.2: $\mathrm{S}^{t+1}=$ run-for ${ }_{\mathrm{r}^{\prime \prime}}$ or run-back ${ }_{\mathrm{r}}$ " according to $\mathrm{s}^{\mathrm{t}}$ is delay - I for" or delay-i-back $\mathrm{r}_{\mathrm{r}}$ for some I $\varepsilon$ and $\mathrm{p}^{\mathrm{t}+1}=\mathrm{p}^{\mathrm{t}}+\mathrm{r}^{\prime \prime}$. In this case ( $\left.w^{\prime \prime}, k^{\prime \prime}\right)$ happens to be same as in a. 2 .

CASE C.1: $\mathrm{S}^{t+1}=$ back $_{\mathrm{r}^{\prime \prime}}$ and $\mathrm{P}^{\mathrm{t}+1}=\mathrm{P}+\mathrm{r}^{\prime \prime}$

In this case also (w", k") happens to be same as in a.2.

CASE C.2: $P+r$ " is blocked.

In this case $\mathrm{P}+\mathrm{r}$ " is blocked and it does not change its inscription. It need not be considered since the given labyrinth is open.

THeOrem 5.8: A mouse which can master every dynamic labyrinth with a way of escape can be constructed.

Proof: The proof follows from lemma 5.6 as $\mathrm{U}_{5}^{\mathrm{c}}$ is verified with all possible cases.

\section{Conclusion}

In this paper we prove the existence of an automaton by constructing the printing mouse $\mathrm{U}_{5}^{c}$ step by step which can escape the given labyrinth even in the presence of moving obstacles inside the labyrinth. These results we can extend further and show the coordination of a team of automata for finding a way of escape. Moreover, the planar labyrinth over rectangular grid can be extended to regular tessellations to generalize the neighborhood patterns.

\section{Acknowledgements}

The authors would sincerely like to thank management of Bharath University, Chennai, India for their support and encouragement. Moreover the authors would like to thank Prof. Ponnammal Natarajan, former Research Director, Anna University, Chennai for her motivation and guidance. 


\section{References}

1. Active-Robots (n.d.) (2008). Cruiser Maze Solver Robot. Available from: http://www.microrobot.co.kr, http://www. activerobots.com/products/robots/cruiser-details-2.shtml.

2. Brüggemann B (2006). Entkommen aus unbekannten labyrinthen mit einbahnstrassen, Master's thesis, Rheinische Friedrich Wilhelms Universität Bonn.

3. Brüggemann B, Kamphans $\mathrm{T}$ et al. (2007). Leaving an unknown maze with one-way roads, in Abstracts 23nd European Workshop Computational Geometry, Graz, Austria, 90-93.
4. Muller H (1977). A one symbol printing automation escaping from every labyrinth, Computing Springer Verlag, vol 19, 95-110.

5. Muller H (1971). Endliche automaten und labyrinthen, Elecktronishe Informations verarbeitung und Kybernetik, vol 7(4), 261-264.

6. Muller H (1971). Stack automaten in labyrinthen, Archiv Für Mathematische Logik Und Grundlagenforschung, vol 14 (3-4), 127-134.

7. Nolfi S, and Floreano D (2000). Evolutionary robotics: the biology, intelligence, and technology of self-organizing machines (Intelligent Robotics and Autonomous Agents), Bradford Books. 